\title{
Diagnostic Value and Safety of Medical Thoracoscopy in the Management of Exudative Pleural Effusion
}

\author{
Mehmet Akif Özgül ${ }^{1}$, Erdoğan Çetinkaya ${ }^{1}$, Elif Tanrıverdi' ${ }^{1}$, Mustafa Çörtük ${ }^{2}$, \\ Murat Acat ${ }^{2}$, Şule Gül ${ }^{1}$, Ekrem Cengiz Seyhan ${ }^{3}$, Derya Özden Omaygenç ${ }^{4}$, \\ Hasan Akın ${ }^{5}$, Kenan Abbaslı ${ }^{1}$, Hilal Onaran ${ }^{6}$
}

\begin{abstract}
${ }^{1}$ Clinic of Chest Diseases, Yedikule Chest Diseases and Thoracic Surgery Training and Research Hospital, İstanbul, Turkey ${ }^{2}$ Department of Chest Diseases, Karabük University School of Medicine, Karabük, Turkey ${ }^{3}$ Department of Chest Disease, Medipol Universty School of Medicine, İstanbul, Turkey ${ }^{4}$ Clinic of Anesthesiology, Yedikule Chest Diseases and Chest Surgery Education and Research Hospital, İstanbul, Turkey ${ }^{5}$ Clinic of Thoracic Surgery, Yedikule Chest Diseases and Chest Surgery Education and Research Hospital, İstanbul, Turkey ${ }^{6}$ Clinic of Chest Disease, Merzifon Kara Mustafa Paşa State Hospital, Amasya, Turkey
\end{abstract}

\begin{abstract}
Objective: Medical thoracoscopy is a minimally invasive procedure that is performed by experienced pulmonologists under local anesthesia and conscious intravenous sedation. It allows direct observation and evaluation of the pleural space. Our aim is to evaluate the diagnostic efficacy and safety of this procedure while presenting our results of medical thoracoscopy performed by rigid thoracoscopy in our clinic.
\end{abstract}

Methods: Thirty-seven patients who had gone thorough medical thoracoscopy between March 2011 and August 2014 were evaluated retrospectively.

Results: Of these 37 patients, 26 were male and the average age was $50.94 \pm 15.38$ years. Fourteen patients had right-sided pleural effusion, whereas 23 had left-sided pleural effusion. Closed pleural biopsy was performed previously in 16 patients with no diagnostic results. In 36 patients (97.3\%), a specific diagnosis was achieved. One patient, diagnosed as lymphocytic pleuritis by medical thoracoscopy, underwent decortication and the pathology was consistent with biphasic malignant pleural mesothelioma. Another patient, diagnosed as chronic nonspecific pleuritis with medical thoracoscopy, underwent decortication and the diagnosis was fibrinous pleuritis characterized by extensive fibrosis. Three patients had expansion defects during the post-operative period. Hemothorax occurred in one patient that died of respiratory failure on day 34 of hospitalization. The median length of stay in the hospital after the procedure was 5 days (1-34).

Conclusion: Medical thoracoscopy is a secure procedure with high diagnostic value in the management of exudative pleural effusion.

Keywords: Anesthesia, local, pleural effusion, thoracoscopy

\section{INTRODUCTION}

Medical thoracoscopy is a minimally invasive procedure that enables a pulmonologist to directly visualize the pleural space and take samples from pathological sites (1, 2). Compared to video-assisted thoracoscopic surgery (VATS), which is performed under general anesthesia with double-lumen tracheal intubation, medical thoracoscopy is immensely advantageous since it can be performed with local anesthesia and conscious sedation (3). Several studies show medical thoracoscopy has increased diagnostic rates in cases where thoracentesis and blind pleural biopsy were not diagnostic (4). In our study, we evaluated the diagnostic value and safety of medical thoracoscopy in patients with exudative pleural effusion where clinical, radiologic, and cytological finding were inconclusive.

\section{METHODS}

Thirty-seven patients who had undergone medical thoracoscopy due to exudative pleural effusion in our clinic from March 2011 to August 2014 were studied retrospectively. These patients had a failed diagnosis by classical methods, including thoracentesis and closed pleural biopsy, before medical thoracoscopy. Medical thoracoscopy was performed by a rigid thoracoscope (Karl Storz, Germany). In all, 500 cc of fluid was drained from the pleural cavity and the same of volume air was administered instead to create an iatrogenic pneumothorax prior to the procedure. The patients were positioned 
on their unaffected side. We administered $15-20 \mathrm{~mL}$ of $1 \%$ lidocaine to the dermis, subdermis, intercostal muscles, and parietal pleura as a local anesthetic and a trocar was placed through a 1-1.5 cm incision. Short-acting benzodiazepine (midazolam) for premedication and low-dose propofol, short-acting hypnotic agent, and/or opioids (phentanyl or remiphentanyl) for anesthesia was used. The drug dose was adjusted to have a RAMSEY sedation scale of 2-3. The obtained specimens were inspected in our pathology department.

This retrospective study was conducted in our hospital. Because of this is a retrospective study, informed written consent was not obtained, but informed consent was received from all of the patients before the procedures. This study protocol was approved by the institutional ethics committee.

\section{RESULTS}

Of the 37 patients, 26 were male, 11 were female, and the median age was $50.94 \pm 15.38$. Fourteen had right-sided pleural effusion. Sixteen had a history of blind pleural biopsy either in our clinic or another medical center; their pathology results were as follows: 9 chronic nonspecific pleuritis (Figure 1); 3 sparse atypical cells, suspicious for malignancy; 1 atypical mesothelial cell proliferation; 1 atypical cell proliferation in fibrohyalinized tissue; and 2 had insufficient material. The most common thoracoscopic finding was diffuse or patchy nodular lesions on the parietal pleura. Tumoral lesions protruding into the pleural space, originating from parietal pleura, pleural thickening, pleural hyperemia, and pleural fibrin webs, were observed in decreasing order of frequency. Medical thoracoscopy was diagnostic in 36 of the patients (97.3\%). The distribution of patients according to diagnosis is summarized in Table 1.

A patient who was diagnosed as lymphocytic pleuritis, but thoracoscopically considered as malignant, underwent decortications and the final diagnosis was biphasic malignant pleural mesothelioma. Of the 9 (24.3\%) patients diagnosed as nonspecific pleuritis, 1 underwent decortication and the final diagnosis was consistent with fibrinous pleuritis characterized by widespread fibrosis. The other 8 patients did not develop malignancy in their 2 year follow-up.

Diagnoses of the patients who had to undergo medical thoracoscopy because they were undiagnosed by blind pleural biopsy are summarized in Table 2. Two cases referred to our clinic with suspicion of pleural malignancy were diagnosed as chronic nonspecific pleuritis; the thoracoscopic appearance of pleura was also supportive of this diagnosis.

Talc pleurodesis was performed in 1 patient with small cell lung carcinoma metastasis, 1 patient with malignant pleural mesothelioma, 2 patients with clear cell carcinoma, 2 patients with non-small cell lung carcinoma, and 1 patient with chronic necrotizing granulomatosis.

During post-operative follow-ups, the complication rate was $19 \%$. Four patients had subcutaneous emphysema, 3 patients had to undergo prolonged chest tube drainage due to expansion failure. One of these patients developed hemothorax that required transfusion but was controlled spontaneously. However, the patient died on the 34 th day of admission due to respiratory failure. The median post-operative hospital stay was 5 days (minimum-maximum: 1-34).

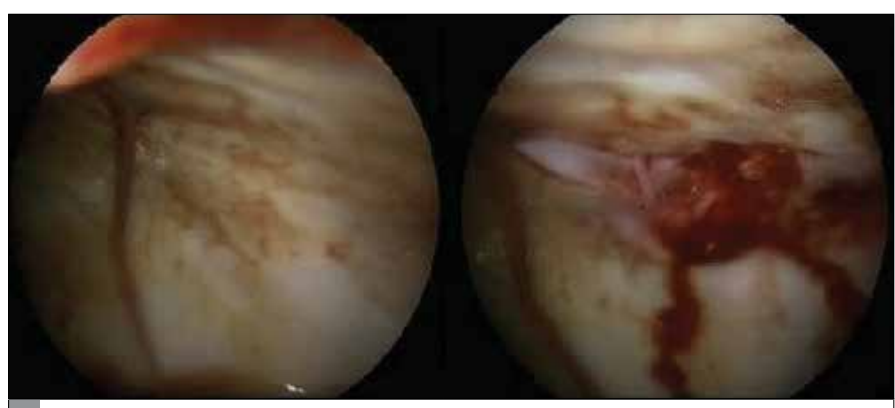

Figure 1. Thoracoscopic appearance of the patient whose blind pleural biopsy was reported as atypical glandular cells with a suspicion of malignancy. Final diagnosis was nonspecific pleuritis

Table 1. Distribution of patients according to diagnosis

\begin{tabular}{|l|c|}
\hline Cytopathologic diagnosis & $\begin{array}{c}\text { Number of patients } \\
(\mathbf{n}=37)\end{array}$ \\
\hline Tuberculosis pleural effusion & 13 \\
Malignant pleural mesothelioma & 5 \\
Non-small cell lung cancer metastasis & 2 \\
Small cell lung cancer metastasis & 1 \\
Breast cancer metastasis & 1 \\
Renal cell cancer metastasis & 2 \\
Larynx cancer metastasis & 1 \\
Primary pleural B-cell lymphoma & 1 \\
Benign pleural asbestosis & 1 \\
Chronic nonspecific pleuritis* & 9 \\
\hline Total & $36(\% 97.3)$ \\
\hline
\end{tabular}

*Chronic nonspecific pleuritis was confirmed by decortication operation of one patient and by the 2 year follow-up of eight patients

\section{DISCUSSION}

In our study, medical thoracoscopy is seen as a useful diagnostic method with high diagnostic yields (97.3\%), low complication rates (19\%), and short hospital stays (5 days) in the management of exudative pleural effusion.

$75 \%$ of all patients with pleural effusion were diagnosed with analysis of the pleural fluid obtained by thoracentesis (5). In cases where thoracentesis fails, blind pleural biopsy or imaging-assisted pleural biopsies are required. Medical thoracoscopy has become a popular alternative method since blind pleural biopsy has low diagnosis rates and surgical pleural biopsy requires general anesthesia, single-lung ventilation, and longer hospital stays (5). Several studies comparing medical thoracoscopy to pleural fluid cytology and/or blind pleural biopsy report a $93 \%$ diagnostic rate with rigid thoracoscopy $(6,7)$. Medical thoracoscopy also has the advantage of enabling the clinician to take several biopsies from the diaphragm and visceral pleura (8). Direct visualization of the pleura during the procedure helps the clinicians form an early opinion and a better chance at patient management (9).

Our study had a high diagnosis rate of $97.3 \%$. Two of our patients were referred to our clinic because blind pleural biopsy findings were atypical of glandular cells. Final diagnosis was nonspecific pleuritis, 
Table 2. Diagnosis of the patients who were undiagnosed by blind pleural biopsy

\begin{tabular}{|c|c|}
\hline $\begin{array}{l}\text { Result of blind } \\
\text { pleural biopsy }\end{array}$ & $\begin{array}{l}\text { Result of medical } \\
\text { thoracoscopic biopsy }\end{array}$ \\
\hline $\begin{array}{l}\text { Atypical mesothelial cell } \\
\text { proliferation }\end{array}$ & $\begin{array}{l}\text { Biphasic malignant pleural } \\
\text { mesothelioma }\end{array}$ \\
\hline Chronic nonspecific pleuritis & Non-small cell lung carcinoma metastasis \\
\hline Chronic nonspecific pleuritis & $\begin{array}{l}\text { Primary pleural B-cell lymphoma } \\
\text { (Figure 1) }\end{array}$ \\
\hline Sparse atypical cells & Chronic nonspecific pleuritis \\
\hline Suspicion of malignancy & $\begin{array}{l}\text { Epithelioid malignant pleural } \\
\text { mesothelioma }\end{array}$ \\
\hline Insufficient material & $\begin{array}{l}\text { Epithelioid malignant pleural } \\
\text { mesothelioma }\end{array}$ \\
\hline Chronic nonspecific pleuritis & Chronic nonspecific pleuritis \\
\hline Chronic nonspecific pleuritis & Lymphocytic pleuritis \\
\hline $\begin{array}{l}\text { Atypical cell proliferation of } \\
\text { fibrohyalinized tissue }\end{array}$ & Larynx carcinoma metastasis \\
\hline Chronic nonspecific pleuritis & Benign pleural asbestosis \\
\hline $\begin{array}{l}\text { Atypical glandular cells, } \\
\text { suspicion of malignancy }\end{array}$ & Chronic nonspecific pleuritis \\
\hline Chronic nonspecific pleuritis & Renal cell carcinoma metastasis \\
\hline Chronic nonspecific pleuritis & Chronic nonspecific pleuritis \\
\hline Chronic nonspecific pleuritis & Chronic necrotizing inflammation \\
\hline Chronic nonspecific pleuritis & $\begin{array}{l}\text { Chronic non-necrotizing } \\
\text { inflammation }\end{array}$ \\
\hline Insufficient material & Chronic necrotizing inflammation \\
\hline
\end{tabular}

Table 3. Comparison of similar studies in regard to complication rates and duration of hospitalization

\begin{tabular}{|l|c|c|}
\hline Hansen et al. (12) & $\begin{array}{c}\text { Complication } \\
(\%)\end{array}$ & $\begin{array}{c}\text { Duration of hospital stay } \\
\text { (average days) }\end{array}$ \\
\hline Alrawi et al. (13) & 10 & -na \\
Metintaş et al. (8) & 40.3 & -na \\
Haridas et al. (14) & 10.3 & - na \\
\hline Blanc et al. (4) & - na & 19.93 \\
\hline DeGroot et al. (15) & - na & 14.1 \\
\hline Our study & 19 & 6.7 \\
\hline na: Not applicable & & 5 (range 1-34) \\
\hline
\end{tabular}

achieved by medical thoracoscopy, where the visual findings thoracoscopically were inconsistent with malignancy. The patients did not develop malignancy in their follow-up. A patient who was diagnosed as lymphocytic pleuritis, but thoracoscopically considered as malignant, underwent decortication and the final diagnosis was biphasic malignant pleural mesothelioma. These cases show the importance of visual assessment in the diagnoses.
Studies show that medical thoracoscopy has a significantly lower systemic complication and mortality rate compared to surgical thoracoscopy and thoracotomy $(9,10)$. Subcutaneous emphysema, localized infection of the incision site, hypotension, fever, atrial fibrillation during the procedure are minor; empyema, hemorrhage, tumor seeding in port site, bronchopleural fistula, pneumonia, prolonged air-leak and re-expansion pulmonary edema are the major complications reported from various studies (11). The complication rates in our study were similar to the literature; the post-operative hospitalization period was shorter in our study (Table 3$)(4,8,12-15)$. The most common complication was subcutaneous emphysema; however, these patients had similar hospitalization days compared to the rest of the patients. One patient who had pleural metastatic larynx carcinoma developed hemothorax that required transfusion. Although hemorrhage was controlled spontaneously, the patient died on the $34^{\text {th }}$ day of admission due to respiratory failure.

A $9 \%$ to $50 \%$ of patients undergoing medical thoracoscopy due to pleural effusion were diagnosed with nonspecific pleuritis $(16,17)$. Two pathways are suggested in the management of these patients; "wait and see" or "decide based on the patient." Deciding based on the patient involves the clinician's visual assessment of the pleura thoracoscopically. If there is a suspicion of malignancy, re-thoracoscopy or surgery is recommended. If the lesions are considered benign, the patient should be monitored; however, criteria for the follow-up period or methods are yet to be defined (18). In our study, the rate of nonspecific pleuritis was $24.3 \%$. Two patients were undiagnosed, but were highly suspicious for malignancy. Of these two patients, one was diagnosed as nonspecific pleuritis after decortication whereas the other was diagnosed as mesothelioma after surgery. The other patients diagnosed as nonspecific pleuritis were thoracoscopically considered as benign so they were monitored. After considering these findings, the "decide based on the patient" is regarded as the more suitable approach.

In diseases where local tumoral invasion is common in biopsy sites, and more often than not radiotherapy is required for these sites, such as malignant mesothelioma, it is crucial to minimize the number of diagnostic and therapeutic procedures. Medical thoracoscopy enables talc pleurodesis in the same procedure where visual assessment is consistent with malignancy (19). In our study, talc pleurodesis was performed on seven patients due to visual assessment of malignant disease. However, one of these patients was later diagnosed as necrotizing granulomatous inflammation. The reason for this situation is merely because this was our first medical thoracoscopy patient.

\section{CONCLUSION}

We would like to state that medical thoracoscopy should be considered in patients with exudative pleural effusion who cannot be diagnosed by thoracentesis and closed pleural biopsy. This enables the clinician to sample the pleura while seeing the pleural cavity. It has a high diagnosis but low morbidity and mortality rates, short hospital stays and no requirement for ventilation.

Ethics Committee Approval: Ethics Committee Approval: Ethics committee approval was received for this study from the ethics committee of İstanbul Medipol Universty.

Informed Consent: Written informed consent was obtained from patients who participated in this study. 
Peer-review: Externally peer-reviewed.

Author Contributions: Concept - M.A.Ö., E.Ç., E.T., E.C.S.; Design - M.A.Ö., E.Ç., E.T., M.Ç., M.A., E.C.S.; Supervision - M.A.Ö., E.Ç., E.T., M.Ç., M.A.; Resources M.A.Ö., E.Ç., E.T., M.Ç., M.A., D.Ö.O.; Materials - M.A.Ö., E.Ç., E.T., D.Ö.O., K.A., H.O., E.C.S., H.A.; Data Collection and/or Processing - E.T., K.A., Ş.G.; Analysis and/or Interpretation - M.A.Ö., E.Ç., E.T., M.Ç., M.A.; Literature Search - E.T., M.Ç., H.O.; Writing Manuscript - M.A.Ö, E.Ç., E.T., M.Ç.; Critical Review - E.Ç., M.A.Ö.; Other - M.A., K.A., H.A., H.O.

Conflict of Interest: No conflict of interest was declared by the authors.

Financial Disclosure: The authors declared that this study has received no financial support.

\section{REFERENCES}

1. Tutar N. Medical Thoracoscopy. Plevra Bülteni 2013; 1: 9-13.

2. Wang F, Tong Z, Wang Z, Wang X, Zhan X, Shi H. Application of medical thoracoscopy in diagnosis of sarcoidosis-related pleural effusion. Respirol Case Rep 2014; 2: 99-101. [CrossRef]

3. Rodriguez-Panadero F, Janssen JP, Astoul P. Thoracoscopy: general overview and place in the diagnosis and management of pleural effusion. Eur Respir J 2006; 28: 409-22. [CrossRef]

4. Blanc F, Atassi K, Bignon J, Housset B. Diagnostic value of medical thoracoscopy in pleural disease: A 6-year retrospective study. Chest 2002; 121: 1677-83. [CrossRef]

5. Skalski JH, Astoul PJ, Maldonado F. Medical thoracoscopy. Semin Respir Crit Care Med 2014; 35: 732-43. [CrossRef]

6. Parrish S, Browning RF, Turner JF Jr, Zarogoulidis K, Kougioumtzi I, Dryllis $\mathrm{G}$, et al. The role for medical thoracoscopy in pneumothorax. J Thorac Dis 2014; 6: 383-91.

7. Diacon AH, Van de Wal BW, Wyser C, Smedema JP, Bezuidenhout J, Bolliger CT, et al. Diagnostic tools in tuberculous pleurisy: a direct comparative study. Eur Respir J 2003; 22: 589-91. [CrossRef]
8. Metintas M, Ak G, Dundar E, Yildirim H, Ozkan R, Kurt E, et al. Medical thoracoscopy vs $C T$ scan-guided abrams pleural needle biopsy for diagnosis of patients with pleural effusions. A randomized, controlled trial. Chest 2010; 137: 1362-8. [CrossRef]

9. Kong XL, Zeng HH, Chen Y, Liu TT, Shi ZH, Zheng DY, et al. The visual diagnosis of tuberculous pleuritis under medical thoracoscopy: a retrospective series of 91 cases. Eur Rev Med Pharmacol Sci 2014; 18: 1487-95.

10. Michaud G, Berkowitz DM, Ernst A. Pleuroscopy for diagnosis and therapy for pleural effusions. Chest 2010; 138: 1242-6. [CrossRef]

11. Rahman NM, Ali NJ, Brown G, Chapman SJ, Davies RJ, Downer NJ, et al. Local anaesthetic thoracoscopy: British Thoracic Society Pleural Disease Guideline 2010. Thorax 2010; 65: 54-60. [CrossRef]

12. Hansen M, Faurschou P, Clementsen P. Medical thoracoscopy, results and complications in 146 patients: a retrospective study. Respir Med 1998; 92: 228-32. [CrossRef]

13. Alrawi SJ, Raju R, Acinapura AJ, Cunningham JN Jr, Cane JS. Primary thoracoscopic evaluation of pleural effusion with local anesthesia: an alternative approach. JSLS 2002; 6: 143-7.

14. Haridas N, Suraj KP, Rajagopal TP, James PT, Ravindran C. Medical thoracoscopy vs closed pleural biopsy in pleural effusions: A randomized controlled study. J Clin Diagn Res 2014; 8: 1-4. [CrossRef]

15. DeGroot $M$, Walther $G$. Thoracoscopy in undiagnosed pleural effusions. $S$ Afr Med J 1998; 88: 706-11.

16. Davies HE, Nicholson JE, Rahman NM, Wilkinson EM, Davies RJ, Lee YC. Outcome of patients with nonspesific pleuritis/fibrosis on thoracoscopic pleural biopsies. Eur J Cardiothorac Surg 2010; 38: 472-7. [CrossRef]

17. Janssen JP. Why you do or do not need thoracoscopy. Eur Respir Rev 2010; 19: 213-6. [CrossRef]

18. Metintas M, Ak G, Cadirci O, Yildirim H, Dundar E, Metintas S. Outcome of patients diagnosed with fibrinous pleuritis after medical thoracoscopy. Respir Med 2012; 106: 1177-83. [CrossRef]

19. Yıldırım H. Medical thoracoscopy in the management of malignant pleural effusion. Eurasian J Pulmonol 2013; 15: 77-81. 